\title{
El espejo y la máscara: dos versiones de Alexander Selkirk en Jorge Luis Borges y William Cowper
}

\section{The Mirror and the Mask: Two Versions of Alexander Selkirk in Jorge Luis Borges and William Cowper}

\author{
Gabriel LinARES GONZÁLEZ \\ Facultad de Filosofía y Letras \\ Universidad Nacional Autónoma de México
}

\section{Resumen}

En 1963, Jorge Luis Borges publicó un soneto titulado "Robinson Crusoe". Posteriormente, cambió el nombre de su composición a "Alexander Selkirk". El presente artículo explica dicho cambio como un intento por parte de Borges por subvertir la figura icónica del náufrago emprendedor, representada no sólo por Crusoe sino por los recuentos contemporáneos del Selkirk histórico, una de las inspiraciones de Defoe. Por otro lado, se compara el poema de Borges con una de sus posibles fuentes, un texto del poeta de finales del siglo XVIII William Cowper. Ambos poemas están escritos en una primera persona cuya voz poética se identifica con Selkirk, por lo que pueden ser estudiados como monólogos dramáticos.

Palabras clave: soneto, monólogo dramático, Jorge Luis Borges, William Cowper, literatura comparada

\begin{abstract}
In 1963, Jorge Luis Borges published a sonnet titled "Robinson Crusoe". He later changed the title to "Alexander Selkirk". The present paper explains such a change as an attempt on the part of Borges to subvert the iconic figure of the resourceful castaway, as represented not only by Defoe's Crusoe but also by Selkirk, one of Defoe's inspirations, as he was depicted by contemporary chronicles. This paper also compares Borges's Selkirk with the one depicted by the 18th-century poet William Cowper, and suggests that the latter's may have been a possible inspiration for Borges. Since in both compositions the poetic voice is to be identified with Selkirk, it is possible to study both poems as instances of dramatic monologues.
\end{abstract}

Keywords: sonnet, dramatic monologue, Jorge Luis Borges, William Cowper, comparative literature 
El presente artículo ofrece una lectura del soneto "Alexander Selkirk" (1963), de Jorge Luis Borges (1899-1986), en conjunción con el poema "Verses, Supposed to Be Written by Alexander Selkirk" (1782), del poeta británico William Cowper (1731-1800). Aunque creo que el poema de Cowper influyó en el del argentino, no pretendo demostrar esto más allá de toda duda. No estoy seguro de que sea posible en términos absolutos, pero ofrezco evidencia de ello apoyándome en las similitudes entre ambos textos. Mi intención primordial es, más bien, llevar a cabo un comentario en el que ambos poemas se iluminen recíprocamente y, acaso, también iluminen, por razones que se verán a continuación, a Robinson Crusoe, la célebre novela de Defoe que cumplió en 2019 su tercer centenario.

Según Nicolás Helft (1997: 132), el "Alexander Selkirk" de Borges fue publicado en 1964, en la cuarta edición del volumen Obras completas, dentro del poemario titulado El otro, el mismo. No obstante, en el segundo tomo de Euvres complètes, la edición francesa de las obras de Borges, la nota que acompaña al soneto apunta que el poema fue publicado "sous le titre 'Robinson Crusoe' dans Jueves de correo, no. 21, Buenos Aires, 21 novembre 1963, p. 1" (Borges, 1999a: 1208), y añade en la misma página que "Le titre définitif ["Alexander Selkirk"], moins évident, est le nom de un marin écossais dont les aventures inspirèrent Daniel Defoe pour Robinson Crusoé [sic]". Presento a continuación el texto tal como se incluye en la edición de Obra poética de 1978, la última de sus poemas reunidos en la que el autor argentino introdujo cambios (Helft, 1997: 130). Dado que no se cuenta con ediciones críticas de la obra de Borges, ${ }^{1}$ esta edición representa, al menos en lo que toca a la poesía escrita hasta La moneda de hierro (1976), la última voluntad del poeta, si bien el concepto mismo de "última voluntad autorial" y la autoridad de dicho concepto son, desde luego, problemáticos. El poema (Borges, 1978: 212) es el siguiente:

Sueño que el mar, el mar aquel, me encierra

y del sueño me salvan las campanas

de Dios, que santifican las mañanas

de estos íntimos campos de Inglaterra.

${ }^{1}$ La "edición crítica" que publicó Emecé en tres volúmenes entre 2009 y 2011 no es tal, en la medida en que no registra sino en muy contados casos las variantes, en ocasiones numerosas, de los textos de Borges y repite inexactitudes de versiones anteriores. Para poner tan sólo un ejemplo, en esa edición el primer verso del poema que nos ocupa acentúa la palabra "aquél", tal como aparece en la edición de las Obras completas (896) de 1974. La edición de Obra poética de 1978 elimina este acento de forma acertada, a mi modo de ver. Los ejemplos se pueden multiplicar y son mucho más graves que éste. La edición francesa, a la que ya me he referido, editada por Jean Pierre Bernès, es mucho más confiable, y contó también con la colaboración del autor. No obstante, tampoco es una edición crítica en un sentido estricto, no sólo porque tampoco da cuenta de todas las variantes, sino porque es una traducción no bilingüe al francés de la obra de Borges. 
[5] Cinco años padecí mirando eternas cosas de soledad y de infinito, que ahora son esa historia que repito, ya como una obsesión, en las tabernas.

Dios me ha devuelto al mundo de los hombres, [10] a espejos, puertas, números y nombres, y ya no soy aquél que eternamente

miraba el mar y su profunda estepa ¿y cómo haré para que ese otro sepa que estoy aquí, salvado, entre mi gente?

Antes de proceder con el comentario del poema, detengámonos un momento más en el personaje que le da título. Como apunta la edición francesa de las obras de Borges, "Alexander Selkirk" es el nombre de un marinero escocés que fue una de las principales fuentes de inspiración de Daniel Defoe para la creación de su náufrago ficticio. Entre 1704 y 1709, Selkirk (1676-1721), después de haber abandonado el barco de cuya tripulación formaba parte, debido a una diferencia que tuvo con su capitán, vivió solo en una de las islas del Archipiélago de Juan Fernández. Al cabo de este tiempo, fue salvado por un barco inglés y regresado unos años más tarde a Inglaterra (Defoe, 1994: 227-238). En su prólogo a Moll Flanders, Borges informa que "Defoe [...] mantuvo en el puerto de Bristol un largo diálogo con Alexander Selkirk, que vivió cuatro años y cuatro meses en la isla de Juan Fernández, al oeste de Chile, y que sería el prototipo de Defoe" (1996: 499).

La historia de Selkirk, como muestran la novela de Defoe, el poema de Cowper y algunos otros recuentos, generó vivo interés. Entre dichos recuentos, se encuentran los de Edward Cooke y Woode Rogers, oficial y capitán, respectivamente, de la expedición que encontró a Selkirk. También existe un artículo sobre Selkirk, obra de Richard Steele (1672-1729), el célebre periodista y ensayista. La imagen de Selkirk que nos llega de las relaciones de sus aventuras hechas en el siglo XVIII es básicamente afín a la del protagonista de Robinson Crusoe. El carácter de dicha imagen se puede resumir en el siguiente pasaje del texto de Steele, de 1713. Dice el periodista: "This plain Man's Story is a memorable Example, that he is happiest who confines his Wants to his natural Necessities; and he that goes further in his Desires, increases his Wants in Proportion to his Acquisitions; or to use his own Expression, I am now worth 800 Pounds, but shall never be so happy, as when I was not worth a farthing" (Steele, 1994: 238). Selkirk se convierte, en la prosa de Steele, en un "ejemplo". El escritor incluso llega a decir del marinero que "The Man frequently bewailed his Return to the World, which could not, he said, with all its Enjoyments, restore him to the Tranquility of his own solitude" (238). Dicha tranquilidad, por supuesto, está asociada con el ejercicio de la piedad cristiana: "It was his Manner to use stated Hours and Places for Exercises of Devotion" (237). 
Para Steele, como para otros, Selkirk es un emblema del estoicismo, la industria y la fe protestante, así como del hombre corrompido por la sociedad, que se revierte favorablemente a una condición virtuosa y genuinamente cristiana gracias a su aislamiento. Dice, por ejemplo, Woode Rogers, en su relato de 1712:

But whatever there is in these Stories, this of Mr. Selkirk I know to be true; and his Behaviour afterwards gives me Reason to believe the Account he gave me how he spent his time, and bore up under such an Affliction, in which nothing but the Divine providence could have supported any Man. By this one may see that Solitude and retirement from the World is not such an unsufferable State of Life. (1994: 235)

Ciertamente, el inicio de la estancia forzada del personaje en la isla lo hace sentir miedo y tristeza, pero las narraciones contemporáneas dan cuenta de su gradual desarrollo y del dominio que alcanza sobre su entorno. Apunto aquí otro pasaje de Rogers:

He diverted and provided for himself as well as he could; but for the first eight months had much ado to bear up against Melancholy, and the Terror of being left alone in such a desolate place. He built two Hutts, [...] and employ'd himself in reading, singing Psalms, and praying; so that he said he was a better Christian while in this solitude or than, he was afraid, he should ever be again. (1994: 232)

Rogers, curiosamente, también anota este otro recurso de Selkirk asociado con la trascendencia de la melancolía: “After he had conquer'd his Melancholy, he diverted himself sometimes by cutting his Name on the Trees, and the Time of his being left and Continuance there" (233). No sólo la piedad cristiana, sino también la cuenta del tiempo y la insistencia en el nombre propio han contribuido a la salvación de Selkirk. Recordemos aquí que, según Steele, los "Exercises of Devotion” tenían lugar en "Stated Hours and Places".

Lo que dijo Patricia Meyer Spacks sobre Robinson Crusoe es aplicable, con pequeños ajustes, a las crónicas sobre Selkirk: "The 2 [sic] most widely accepted readings of Robinson Crusoe concentrate on its status as 'spiritual autobiography' and on Crusoe's role as exemplar of 'economic man"' (Spacks, 1976: 434). Ciertamente ninguno de los relatos sobre Selkirk usa la primera persona que asociamos con la autobiografía, pero indudablemente el crecimiento espiritual y el económico (la administración de una isla que se transforma en una casa) van de la mano en los recuentos de Rogers y Steele, como hemos visto. ${ }^{2}$ Tan automático es este desarrollo paralelo que se puede conjeturar que el Selkirk de las crónicas se aproxima en mayor grado al emblema que al individuo real. Posteriormente, le tocó al marinero escocés el destino de muchos

\footnotetext{
2 Justo es decir que la primera y breve noticia del rescate y la aventura de Selkirk en la isla, la de Edward Cooke, del mismo año que la de Rogers - 1712 - no pone atención al desarrollo espiritual del personaje: "he continu'd four Years and four Months, living on Goats and Cabagges that grow on Trees, Turnips, Parsnips \&c" (Cooke, 1994: 230).
} 
individuos que inspiraron obras literarias: ser sustituidos en la memoria colectiva por su alter ego ficticio, que aquí cobró la forma del náufrago de Defoe. "Sólo perduran en el tiempo las cosas / que no fueron del tiempo", escribió Borges al final del breve poema "Eternidades" (1978: 432).

Borges retoma el nombre "moins évident" de Selkirk y lo pone en lugar del de Crusoe en su soneto. El lector puede ejecutar varios actos de lectura a través de este título. Hasta este punto, me he concentrado en el origen histórico del nombre y en los inicios de la transformación del hombre en figura literaria. Sin embargo, el soneto y su título también nos permiten subvertir y reinventar la imagen que hemos recibido de Selkirk. Además, con ayuda del texto de Borges, podemos restituir a la memoria literaria el poema de Cowper y establecer relaciones que tal vez no sean casuales entre ambos textos. Las páginas que siguen se concentran en los dos poemas y en la figura del náufrago que representan.

Ya hemos dicho que la composición de Borges es un soneto. Pero las rimas de los sonetos en la obra de este poeta no corresponden generalmente con las del soneto español. Las de "Alexander Selkirk" se pueden describir de la siguiente manera: abba cddc eef ggf. Dicho esquema se acerca en un aspecto importante al del soneto tradicional francés, cuya combinación suele ser abba abba ccd ede (Aquien y Molinié, 1999: 685-690). Los versos 9 y 10 ("Dios me ha devuelto al mundo de los hombres / a espejos, puertas, números y nombres") constituyen un dístico que divide al poema en tres secciones, definidas por la métrica, no necesariamente por la disposición tipográfica; la primera conformada por dos cuartetos (abba cddc); la segunda, definida por el dístico ya mencionado (ee), y la última constituida por otro cuarteto (fggf). Mientras que en francés los cuartetos iniciales comparten las mismas rimas, ello no ocurre en el caso de este espécimen. Tipográficamente, sin embargo, el soneto se presenta distribuido en la forma habitual, en dos cuartetos y dos tercetos, del mismo modo que en el soneto francés. Estas características tienen, evidentemente, repercusiones importantes en los efectos estéticos del poema que me ocupa, como veremos más adelante.

El poema es, también, un "monólogo dramático". Esto quiere decir que en el poema habla Selkirk o, para decirlo de una forma más precisa desde los puntos de vista lingüístico y literario, respectivamente, el sujeto de la enunciación o la voz poética se identifica con Selkirk. Recordemos que, en los monólogos dramáticos de Browning (1812-1889), según la Introducción a la literatura inglesa del propio Borges, "personajes reales o imaginarios, Napoleón III y Calibán se muestran y se justifican" (1997: 98). Esta forma poética tuvo gran auge en la Inglaterra victoriana, en los poemas no sólo de Browning, sino también de Tennyson y otros contemporáneos, y su vigencia desde el siglo XIX hasta el presente puede confirmarse si se revisan, por ejemplo, estudios clásicos como The Poetry of Experience (publicado originalmente en 1957) de Robert Langbaum, o el más reciente Dramatic Monologue (2003) de Glennis Byron. El poemario The World's Wife (1999) de Carol Ann Duffy es uno de los ejemplos actuales más célebres de la fecundidad y flexibilidad del monólogo. Cada uno de los estudiosos de esta forma tiene, por supuesto, una opinión diferente de cuáles son los elementos 
esenciales de ésta. En mi opinión, el monólogo se define precisamente por su voz poética, identificable con un personaje imaginario o imaginado que claramente no es el poeta que escribe el poema. En este sentido, el monólogo dramático tiene como recurso principal la prosopopeya, entendida ésta como "The speech of an imaginary person" (Greene y Cushman, 2012: 1120). ${ }^{3}$

La identificación entre la voz poética y Selkirk no es explícita, pero me parece que deja muy poco lugar a dudas. Ciertos elementos del poema se pueden asociar con el título para llevar a cabo tal identificación. El pasaje crucial en lo que respecta a la identidad de la voz poética está acaso en los vv. 5-6: “Cinco años padecí mirando eternas / cosas de soledad y de infinito". Dicho periodo de tiempo, como ya hemos visto en la primera parte de este estudio, coincide más o menos con el que el marinero escocés pasó en la isla de Juan Fernández. Otros elementos del poema se agrupan en torno a este dato para confirmar la identidad de la voz. El demostrativo en la frase "estos íntimos campos de Inglaterra" le da inmediatez al sustantivo que modifica. El lector sabe así que el tiempo en la isla ha pasado. En contraste, la voz hace uso en el primer verso de la palabra "aquel" para referirse al mar como algo lejano.

Ya varios autores han catalogado el poema como monólogo dramático (véase, por ejemplo, Jones [1986: 210], Cervera [1992: 126, 211]), pero, hasta donde tengo noticia, nadie le ha dedicado hasta ahora al poema un análisis detallado. De las varias menciones a este soneto, quiero resaltar una. Sobre él, ha dicho Rolando Costa Picazo, encargado de la "edición crítica" de las obras completas de Borges a la que me he referido antes: "Se trata de un monólogo dramático [...], en que Selkirk, ya de regreso a Inglaterra luego de sus viajes y de pasar cinco años en una isla desierta, echa una mirada retrospectiva sobre su aventurera vida" (Borges, 2010: 547). Llama la atención que Costa Picazo describa los pensamientos del Selkirk de Borges de esta manera. Poco nos dice el poema sobre su "aventurera vida". La mirada del personaje tampoco parece "retrospectiva". En realidad, el poema enfatiza la inmediatez con la que se vive la pasada (y dolorosa) experiencia en la isla. La voz poética se mueve pendularmente entre dos realidades, de las cuales la recordada y soñada, aunque esté en el pasado, parece ser la más vívida.

En el primer verso, "Sueño que el mar, el mar aquel, me encierra", resalta no sólo la referencia a un mar soñado, sino su caracterización como una prisión, no pretérita, sino actual a través del verbo en presente, "encierra". Contrastan con estos versos los tres siguientes, que devuelven a la voz poética a su patria a través de los verbos, también en presente ("y del sueño me salvan las campanas / de Dios, que santifican las mañanas / de estos íntimos campos de Inglaterra" v. 2-3), y a través también de la inmediatez de los "íntimos campos", marcada por medio del demostrativo "estos" (v. 4). Nótese también, en lo que toca a las rimas, el contraste, en el contexto del poema,

\footnotetext{
3 Ahondar en la naturaleza del monólogo dramático excede los objetivos del presente artículo. Creo que la definición que ofrezco aquí es práctica — es decir, funcional- El lector interesado en la historia de la forma y su definición puede acudir al libro de Glennis Byron que menciono arriba.
} 
entre "encierra" e "Inglaterra" y la complementareidad de las palabras "campanas" y "mañanas", que se oponen a la pesadilla nocturna. Vale la pena agregar que el ritmo de los versos también contribuye a este contraste. El primer verso tiene acentos en la primera, cuarta, sexta, octava y décima sílabas ("Suéño que el már, el már aquél me enciérra"), lo cual le da un ritmo acelerado, que incluso podría alguien comparar con el de las olas del mar, y que recuerda, por la acentuación de las sílabas pares, al pentámetro yámbico del inglés. Los versos del 2 al 4, en cambio, presentan todos un ritmo más relajado con sus acentos en la sexta y décima sílabas, en consonancia con la paz que expresa su contenido: el náufrago se encuentra sano y salvo en su patria.

El siguiente cuarteto opone de manera similar sus dos primeros versos (5-6) con los dos últimos (7-8). El periodo de aislamiento tiene unos límites bastante claros ("Cinco años", v. 5), pero es asociado con la frase "eternas / cosas de soledad y de infinito" (vv. 5-6). Claramente, la frase sirve aquí para intensificar el sufrimiento de Selkirk, del mismo modo, por ejemplo, que el verbo "padecí" (v. 5). La palabra "cosas" (v. 6), en su generalidad es, hasta cierto punto, vacía, dado que todo cabe en ella, y se aviene bien tanto con el adjetivo que lo modifica directamente ("eternas") como con los sustantivos que dependen de la preposición "de" en el mismo verso ("soledad" e "infinito"). El consuelo que ofrece el presente es bastante pobre en este cuarteto. En el primero, como se recordará, lo divino ("las campanas de Dios" que "santifican") se oponía a la isla; en el segundo, la voz se sitúa en las "tabernas", lugar opuesto a cualquier ambiente de santidad cristiana. El relato de su experiencia, al que Costa Picazo, como ya apunté, se refiere como su "aventurera vida" poco tiene de agradable. La palabra "repito" (v. 7), cuyo objeto directo es el "relato", se ve violentamente modificada por la frase "como una obsesión". Finalmente, en todo este cuarteto, como en el anterior, las rimas refuerzan las tensiones semánticas presentadas: "infinito" rima con "repito", y "eternas", casi grotescamente, con "tabernas".

La posición del dístico o pareado en el soneto - como se recordará, en los vv. 9-10 - se vuelve aquí especialmente relevante. La contundencia de su rima ("hombres" / "nombres") fortalece, en buena medida, la vuelta al tema de la salvación divina ("Dios me ha devuelto", v. 9). Su fuerza, por otro lado, se ve aumentada por el ritmo paralelo de los acentos, en la cuarta, sexta y décima sílaba de ambos versos. Los sustantivos "números y nombres", por otro lado, pueden recordarnos las crónicas de Steele y Rogers, según las cuales Selkirk encontraba consuelo escribiendo su nombre en los árboles, registrando en ellos los días de su confinamiento o haciendo ejercicios espirituales en lugares y horas determinados.

No deja de haber algunos elementos inquietantes en las connotaciones de estos dos versos, sin embargo. Consideremos la lista de sustantivos que componen el "mundo de los hombres" (v. 9): "espejos, puertas, números y nombres" (v. 10). Recordemos que, según los heresiarcas de Tlön, "los espejos y la cópula son abominables, porque multiplican el número de los hombres" (Borges, 1974: 431). En cuanto a los "números", Carlos Cortínez, quien analiza este verso en cierta profundidad, cita la siguiente opinión del libro clásico La expresión de la irrealidad en la obra de Jorge Luis Borges, de Ana 
María Barrenechea: "La geometría y los números, las más humanas de las creaciones junto con el lenguaje pueden servirle a Borges [...] de metáforas que expresan esa nohumanidad de lo divino, pues su simplicidad alude a una perfección aséptica, sin mezcla de pasiones y de dudas" (Barrenechea citada en Cortínes, 1979: 207). Acaso el sustantivo más inocente y tranquilizador de todos en este verso sea "puertas" dado que, como el mismo Cortínez apunta, "la puerta tiene el valor de la metonimia de la casa o de sus ocupantes" (1979: 206). No deja de dar qué pensar, a pesar de todo, la asociación de "puertas" con "espejos" a través de la yuxtaposición de ambas palabras. Alguna semejanza hay entre ambos objetos. Un espejo parece abrir una entrada a otro lugar.

Por otro lado, el dístico, que en un soneto inglés remataría toda la composición, aquí sólo ofrece, si acaso, un alivio temporal. Después de declarar en el pareado la salvación divina, el poema procede hacia el último cuarteto, que vuelve a situarse en el terreno del movimiento oscilatorio entre la salvación y la desesperación. Mientras que en los dos primeros cuartetos procedemos de la soledad a la liberación, incluso cuando ésta se da en el malestar, como en los vv. 7-8, el último cuarteto procede al revés, como en un espejo con respecto a los otros dos cuartetos: va de la redención a la duda. El último cuarteto puede compararse así con una especie de prisma, que refracta e invierte la imagen de los ocho primeros versos. Los vv. 11-12 enfatizan el consuelo del dístico ("y ya no soy aquél que eternamente / miraba el mar y su profunda estepa"). Aunque la palabra "eternamente" hace eco del adjetivo "eternas" y del sustantivo "infinito" de los versos 5 y 6 , respectivamente, la voz parece haber superado su sueño, pues ahora hace uso de un tiempo que remite al pasado, incluso si éste es el imperfecto ("miraba"). Sin embargo, el sentido de estos versos se completa en la pregunta sin respuesta de los últimos dos versos del poema, que ponen en evidencia la imposibilidad de ser salvado: “¿Y cómo haré para que ese otro sepa / que estoy aquí, salvado, entre mi gente?” (vv. 13-14).

Los dos últimos versos presentan una especie de desdoblamiento de la personalidad de Selkirk. La división se establece de varias formas. La voz poética introduce la palabra "otro" en el v. 13, acompañada del demostrativo "ese", lo cual no sólo distancia a ese "otro" que él mismo es, sino que también lo vincula con el "mar aquel" del primer verso. En contraposición al "otro", la voz poética se vale de la oración "estoy aquí", que denota inmediatez, presencia e identidad, y se autodefine con el verbo "salvado", que nos lleva nuevamente al verso dos y a las campanas, que son allí sujeto del mismo verbo "salvar". Las dos identidades de la voz poética se definen en los espacios de prisión y liberación que representan las dos islas: la desierta y Gran Bretaña, respectivamente. La pregunta sugiere la imposibilidad de su integración. Tal falta de integración, además, se refuerza en la disonancia de las rimas y del ritmo de los versos. No parece sentirse entre "eternamente" (v. 11) y "gente" (v. 14), ni entre "estepa" (v. 12) y "sepa" (v. 13) la complementariedad ni el contraste que existe en las rimas del resto del soneto. Por otro lado, a pesar de que los vv. 13 y 14 tienen acentos en la cuarta, octava y décima sílaba, y en la cuarta, sexta y décima sílaba, respectivamente, también tienen un extraño acento en séptima, lo cual los hace especialmente disonantes en el 
contexto del soneto y en la tradición del soneto en español: “¿Y cómo haré para que é (7)se ótro sépa / que estóy aquí salvá(7)do éntre mi génte?". Dice Domínguez Caparrós (1999) que al endecasílabo con acentos en las sílabas cuarta y séptima, llamado de "gaita gallega", "Desde un punto de vista clasicista, se lo considera falto de la gravedad del endecasílabo" (1999: 139).

El personaje de Borges, como ya he sugerido, presenta una diferencia esencial con el de, por ejemplo, Steele o Rogers. Como se recordará, el Selkirk que nos retrata Steele lamenta incluso haber regresado a la civilización, en tanto que ésta lo ha vuelto consciente de nuevo de los males que aquejan a todo individuo que vive en sociedad. En el caso del soneto de Borges, a pesar de la realidad de su rescate, el personaje no se siente por completo liberado de la isla desierta, que vuelve en sus sueños para atormentarlo. Borges no está interesado en la narración presentada por Steele o Rogers sobre Selkirk. Su marinero está profundamente escindido a causa de su viaje. Costa Picazo compara al personaje con una célebre creación de Samuel Taylor Coleridge (17721834): "es una especie de Viejo marino, el personaje del poema de Coleridge ('The Rime of The Ancient Mariner'), solo que Borges introduce el tema del doble" (Borges, 2010: 547). Como se recordará, en el poema de Coleridge, el marinero está condenado a repetir su historia para conseguir alivio de su extraña aventura en el océano. Dicen los versos 582-585 de la versión del poema de 1817: "Since then, at an uncertain hour, / That agony returns: / And till my ghastly tale is told, / This heart within me burns". No obstante, como se puede ver, contar su historia no le da a Selkirk ningún alivio. Vale la pena resaltar que la comparación de Costa Picazo nos permite notar la lejanía entre el Selkirk de Borges y el de Steele y Rogers e, incluso, el Crusoe de Defoe. El personaje borgesiano se aproxima más a un romántico perdido en su subjetividad que se resiste a los dictados de la lógica. Este Selkirk dividido y especular es, también, profundamente borgesiano. Como ya anuncié, además, creo que hay una sombra más detrás del soneto de Borges — la de William Cowper, quien en 1782 publicó "Verses, Supposed to be Written by Alexander Selkirk, during His Solitary Abode in the Island of Juan Fernandez"-.

Cowper es actualmente un poeta relativamente olvidado, pero, como dice la Norton Anthology of English Literature, uno de esos textos que, se quiera o no, todavía ilustran el canon de la literatura inglesa, y que todavía contiene algunas selecciones de las obras de este poeta, "Blake, Wordsworth, and Coleridge felt close to him, and so did many literary women. No eighteenth-century poet was more beloved" (Greenblatt, Noggle y Lipking, 2012: 3072). Era, de hecho, el poeta favorito de Austen. Cualquiera que haya leído Sense and Sensibility podrá recordar a Marianne Dashwood criticando a Edward Ferrars por leer sin emoción a Cowper: "Oh! mama, how spiritless, how tame was Edward's manner in reading to us last night! I felt for my sister most severely. [...] To read those beautiful lines which have frequently almost driven me wild, pronounced with such impenetrable calmness, such dreadful indifference!" (Austen, 2002: 15-16). En lo que atañe a la periodización de la literatura inglesa, se suele incluir a Cowper en lo que se denomina "The Age of Sensibility", momento que 


\section{$72 \square$ EL ESPEJO Y LA MÁSCARA: DOS VERSIONES DE ALEXANDER SELKIRK}

cierra el neoclasicismo y anuncia el romanticismo. Como por lo menos un par de sus contemporáneos, Christopher Smart y William Blake, la inestabilidad mental fue uno de los principales motores de su obra. A diferencia de Blake, pero como Smart, pasó alguna temporada en el manicomio. Vivió recluido buena parte de su vida, batallando constantemente contra la melancolía y sintiéndose culpable ante Dios por un par de intentos de suicidio.

Borges menciona a Cowper explícitamente en un par de ocasiones en su obra. ${ }^{4}$ Tal vez la referencia menos interesante es la que se encuentra en la "Biografía sintética" (título de una columna que Borges escribía en la revista El Hogar) de T. F. Powys, novelista inglés “de ascendencia ilustre, ya que entre las personas de su sangre están John Donne y William Cowper" (Borges, 1996: 358). Dicha biografía fue publicada el 15 de abril de 1938. En otras dos ocasiones, Borges se refiere a las traducciones que Cowper realizó de la obra de Homero. Una pertenece al famoso ensayo "Las traducciones homéricas". Sobre los esfuerzos de Cowper con Homero, nos dice Borges: "[su traducción] es la más inocua de todas: es literal, hasta donde los deberes del acento miltónico lo permiten" (1996: 243). ${ }^{5}$ El ensayo es originalmente de 1932. Cuatro años más tarde, en una reseña publicada en la revista Sur sobre una traducción de la Odisea ejecutada por T. E. Lawrence, "Lawrence de Arabia", el escritor argentino emitiría un juicio acaso menos severo en sus matices, pero prácticamente igual, sobre las labores del poeta dieciochesco, al mencionar "la rapsodia miltónica de Cowper" (Borges, 1996: 136) para definir su "traducción homérica".

A pesar de la ausencia de más menciones a este poeta inglés en su obra, creo que es posible oír ecos de su poema sobre Selkirk en el poema de Borges pero, como dije al principio, es mi propósito esencial llevar a cabo una lectura comparada de ambos que

${ }^{4}$ La búsqueda de estas referencias se realizó en el Finder’s Guide de la página digital del Borges Center de la Universidad de Pittsburgh y en Rosato y Álvarez (2010).

${ }^{5}$ Justo es decir que Borges no permite al lector juzgar directamente las traducciones de ninguno de los escritores ingleses que menciona en el ensayo, pues los fragmentos que presenta de todas ellas han sido, a su vez, traducidos por él al español. Dice su versión de la de Cowper, que proviene de los vv. 533-537 del canto XI de la Odisea: "Al fin, luego que saqueamos la levantada villa de Príamo, cargado de abundantes despojos seguro se embarcó, ni de lanza o venablo en nada ofendido, ni en la refriega por el filo de los alfanjes, como en la guerra suele acontecer, donde son repartidas las heridas promiscuamente, según la voluntad del fogoso Marte" (241-242). Cowper habría escrito: "At length when we had sacked the lofty town /, Of Priam, laden with abundant spoils / He safe embark'd, neither by spear of shaft / Aught hurt, or in close fight by faulchion's edge / As oft in war befalls, where wounds are dealt / Promiscuous, at the will of fiery Mars" (Borges, 1999b: 72). Un análisis de este pasaje y de su traducción por Borges excede mis objetivos aquí. Pongo, como punto de comparación, estos versos tal como aparecen en traducciones académicas en inglés y en español. La traducción al español es de José Manuel Pabón: "Arrasado por fin el alcázar excelso de Príamo, / con su parte de presa y honor embarcó su navío / sin sufrir ningún daño: no herido por lanza de bronce / ni alcanzado tampoco de cerca, cual suele en la guerra / ocurrir tantas veces, que es ciega la furia de Ares" (Homero, 2007: 213). Presento en inglés la de A. T. Murray, revisada por George E. Dimock: "But after we had sacked the lofty city of Priam, he went on board his ship with the share of his spoil and a noble prize --al unscathed as he was, neither struck with the sharp spear nor stabbed in closed combat, as often befalls in war; for Ares rages confusedly" (Homero, 1998: 439). 
aspira a iluminarlos mutuamente. Presento el texto de Cowper a continuación, tal como se reproduce en la antología editada por Michael Bruce para Everyman en 1999. El texto (Cowper, 1999: 6-7), nos dice (1999: 88), está basado en la edición de los poemas de Cowper de 1800, y atiende también a las ediciones de 1967, de Milford y Russell, y 1980, de Baird y Ryskamp.

I am monarch of all I survey,

My right there is none to dispute;

From the centre all round to the sea, I am lord of the fowl and the brute.

[5] O solitude! where are the charms

That sages have seen in thy face?

Better dwell in the midst of alarms,

Than reign in this horrible place.

I am out of humanity's reach, [10] I must finish my journey alone, Never hear the sweet music of speech;

I start at the sound of my own.

The beasts that roam over the plain,

My form with indifference see;

[15] They are so unacquainted with man,

Their tameness is shocking to me.

Society, friendship, and love, Divinely bestowed upon man,

Oh had I the wings of a dove, [20] How soon would I taste you again!

My sorrows I then might assuage In the ways of religion and truth, Might learn from the wisdom of age, And be cheer'd by the sallies of youth.

[25] Religion! what treasure untold Resides in that heavenly word!

More precious tan silver and gold, Or all that this earth can afford.

But the sound of the church-going bell [30] These valleys and rocks never heard, Ne'er sigh'd at the sound of a knell, Or smil'd when a sabbath appear'd. 
Ye winds, that have made me your sport,

Convey to this desolate shore

[35] Some cordial endearing report

Of a land I shall visit no more.

My friends, do they now and then send

A wish or a thought after me?

$\mathrm{O}$ tell me I yet have a friend,

[40] Though a friend I am never to see.

How fleet is a glance of the mind!

Compar'd with the speed of its flight,

The tempest itself lags behind,

And the swift-wing'd arrows of light.

[45] When I think of my own native land,

In a moment I seem to be there;

But alas! recollection at hand

Soon hurries me back to despair.

But the sea-fowl is gone to her nest,

[50] The beast is laid down in his lair,

Even here is a season of rest,

And I to my cabin repair.

There is mercy in ev'ry place,

And mercy, encouraging thought!

[55] Gives even affliction a grace,

And reconciles man to his lot.

El poema de Cowper cuenta con siete estrofas de ocho versos. Éstas en realidad se componen de dos partes, cada una con rimas alternadas (ababcded). Por lo tanto, el texto puede dividirse en catorce unidades, más que en siete. Cada estrofa es, en realidad, doble. Como el de Borges, éste es un poema en primera persona cuya voz poética es Alexander Selkirk. Por ello, puede considerarse un ejemplo de prosopopeya - es decir, un antecedente del monólogo dramático del siglo XIX- Una vez más, en este poema, la identidad de la voz poética se hace patente no sólo por el título ("Verses, supposed to be written by Alexander Selkirk"), que aquí es mucho más explícito que el de Borges, sino porque las características de la voz son compatibles con las del marinero escocés.

Como en el poema de Borges, el movimiento pendular entre dos actitudes marca el poema. Estas tensiones están enfatizadas en ocasiones por la naturaleza doble de cada estrofa. En la primera, por ejemplo, los cuatro primeros versos realzan el poder de Selkirk, en tanto único señor de la isla. "I am a monarch", dice el v. 1. Los tres siguientes versos expanden este concepto, con un importante límite, como en el soneto del 
argentino: el mar, mencionado en el v. 3. Los siguientes cuatro versos de esta estrofa, por otro lado, parecen contradecir a Steele, en la medida en la que rechazan articular la experiencia de la soledad según el tópico horaciano del beatus ille, que en español se puede resumir en los famosos versos de Fray Luis: "Qué descansada vida / la del que huye el mundanal rüido" ("Oda a la vida retirada", vv. 1-2). De hecho, la voz no sólo se resiste a emplear dicho tópico, sino que lo niega, al calificar la isla como "horrible" (v. 8) y referirse a las virtudes de la soledad como meros "charms that sages have seen" (vv. 5-6).

Un contraste similar puede notarse en la cuarta estrofa. Los primeros cuatro versos alaban, comparándolas con un "treasure untold" (v. 25), las bendiciones de la religión. De hecho, expanden la metáfora haciendo mención explícita de "silver and gold" (v. 27). Los últimos cuatro, sin embargo, marcan la ausencia de dicho tesoro con una imagen que evoca fuertemente los vv. 2-4 del soneto de Borges; las campanas de la iglesia son mencionadas en la forma de una ausencia en los vv. 29-32 de Cowper: "But the sound of the church-going bell / These valleys and rocks never heard, / Ne'er sigh'd at the sound of a knell / Or smil'd when a Sabbath appeared". Una tensión tal vez más sutil se advierte en la última estrofa. El consuelo que el personaje encuentra no tiene tanto que ver con la estoica comprensión del que halla la virtud de la soledad y la simplicidad, sino con el puro cansancio (vv. 49-56):

But the sea-fowl is gone to her nest,

[50] The beast is laid down in his lair,

Even here is a season of rest,

And I to my cabin repair.

There is mercy in every place,

And mercy, encouraging thought!

[55] Gives even affliction a grace,

And reconciles man to his lot.

La misericordia ("mercy") es mencionada dos veces en el último cuarteto (vv. 5354), es cierto, pero la estrofa está determinada más bien por la rima entre "nest" (v. 49) y "rest" (v. 51) de la primera cuarteta. El día siguiente traerá, para Selkirk, una nueva serie de ondulaciones entre el consuelo y la desesperación. El poema de Borges concluye con una pregunta. El de Cowper representa un ciclo de desesperación, cansancio y consuelo.

Vale mencionar también el contraste, aunque asimétrico, que hay en los versos de la sexta estrofa. Los primeros seis versos desarrollan el concepto de la rapidez del pensamiento, comparando a éste con la tempestad y la luz. Gracias su rapidez, Selkirk parece poder transportarse a su patria ("In a moment I seem to be there", v. 46). Los últimos dos versos de la estrofa, sin embargo, niegan tal posibilidad ("But alas! recollection at hand / Soon hurries me back to despair", vv. 47-48). Esos versos parecen reflejar e invertir (los dos términos tienen algo de sinónimos) la primera estrofa del 
poema de Borges, donde Selkirk despierta de su pesadilla y es devuelto a la realidad de su patria. Como puede verse, existen paralelismos y semejanzas entre ambos poemas. Ambos usan el mismo recurso retórico como eje de la composición: la prosopopeya. El desarrollo discursivo es también similar en ambos casos: un movimiento constante entre el consuelo y la desesperación. Las dos composiciones comparten también ciertas imágenes, por ejemplo, las campanas que repican y el pensamiento que permite transportarse entre las dos islas con aparente inmediatez.

Ciertos contrastes y diferencias son dignos de mencionarse. Mientras que Cowper escribe un poema en estrofas de dos unidades cada una, que suelen servirle para crear contrastes, Borges escogió la forma cerrada del soneto. La estructura de Cowper es abierta, pero el discurso del personaje sugiere circularidad; los versos finales insertan los vaivenes del pensamiento del náufrago en el ciclo diurno. Borges hace uso de un dístico en los vv. 9-10 para dividir el soneto en tres partes desiguales (vv. 1-8, vv.9-10, y vv. 11-14, respectivamente). Puede decirse que, de algún modo, la primera se refleja en la tercera. La primera parte consta de dos cuartetos en los que el personaje se mueve, una y otra vez, de la sensación de aislamiento a la salvación. Los últimos cuatro versos invierten ese movimiento y concluyen con una pregunta.

Vistos el uno frente al otro, el poema de Borges es un reflejo invertido (como ya he dicho, estas dos palabras están asociadas) del de Cowper. Borges sitúa a Selkirk después de su aparente salvación; Cowper, antes. Su lectura conjunta sitúa al marinero escocés en un lugar muy diferente de los relatos de Steele y Rogers y, por supuesto, del emprendedor y piadoso Crusoe de Defoe. Ni uno ni otro de los dos textos poéticos en los que me he concentrado aquí constituye una narrativa de progreso gradual. El desarrollo poético de ambos invita aquí, más bien, a la comparación, ya declarada antes, con el círculo, o con el péndulo.

Patricia Meyer Spacks (1976), en el artículo que ya cité anteriormente, estudia dos "autobiografías espirituales" del siglo XVIII, una ficticia y una "real" (tan real como puede ser una autobiografía): la primera es el Robinson Crusoe; la segunda, la que el propio Cowper escribió de su vida en la década de 1760, cuando aún era bastante joven (estaba en sus treinta) y no había escrito todavía algunos de sus poemas más famosos, entre ellos el poema sobre Selkirk. En su texto, Spacks describe las tensiones que una autobiografía de este tipo presenta para su autor al intentar ajustarse a un argumento de desarrollo espiritual marcado por sus propias convenciones narrativas. Nos dice que, en el caso de Cowper, "he expresses through his writing an imaginative and psychic conflict not fully resolved by conversion" (Spacks, 1976: 426). Spacks sostiene también algo que es una consecuencia lógica de su argumentación. Si la autobiografía "espiritual" falsea y modifica los hechos para ajustarse a un cierto esquema narrativo, entonces el verdadero artífice del biografiado no es Dios (o si generalizamos para otras biografías, el destino, las fuerzas históricas, el universo que conspira a favor de uno), sino el autor de la propia autobiografía: "The spiritual autobiography can reveal the intricacies of the imagination: a force leading men toward or away from God, in the living and the telling of lives, a force thus defining his ultimate identity" (434). 
Si en la narrativa autobiográfica el autor tiende a suprimir sin éxito ansiedades que le impedirían dar consistencia a su relato, estos poemas, por el mismo carácter contemplativo pero no narrativo del monólogo dramático (un carácter que comparte con la poesía lírica), le permiten a sus autores concentrarse en lo no resuelto: en esas mismas ansiedades. La lección que nos parecen dar estos dos textos parece un tanto sombría. Incluso si se es "monarch of all", incluso si se es salvado, no todo está resuelto; siempre habrá partes de nosotros reacias a nuestro control absoluto. No somos dueños de nosotros mismos. Aunque sabemos que los textos no tienen por qué darnos lecciones (y tal vez no nos las dan, sino que ciertos lectores las crean a partir de los textos), es posible que se pueda ver esta oscuridad bajo otra luz. En un texto titulado "OdiseoUlises-Sísifo", Adriana Crolla (2007) compara, imprevisiblemente, a Ulises, viajero incansable y exitoso, varón fecundo en recursos, con el Sísifo no sólo de la mitología, sino también con el del ensayo de Camus. Dice Crolla: "en el viaje contemporáneo de Sísifo (ya lo había patentizado el Ulises joyciano) la vuelta se ha vuelto rutina y el trayecto hacia la cima, un itinerario errante hacia la nada" (2007: 248). Dicho itinerario, no obstante, cobra sentido si atendemos, como apunta Crolla, a las palabras de Camus. El francés escribe en las páginas finales de su ensayo: "Mais Sisyphe enseigne la fidélité supérieure qui nie les lieux et soulève les rochers. [...] La lutte elle-même vers les sommets suffit à remplir un cœur d'homme. Il faut imaginer Sisyphe heureux" (2019: 168). Hay que imaginarse a Sísifo dichoso "porque puede descubrir que su roca es su cosa'. [...]. Por ello su destino le pertenece" (Crolla, 2007: 248-249).

Los respectivos Selkirk de Cowper y de Borges pueden compararse con este Sísifo. $\mathrm{Si}$ el de Cowper parece situado en un movimiento cíclico, ya volverá a revivir su salvación espiritual en algún arco de ese ciclo. Consideremos, por otro lado, la conclusión del poema de Borges. Como hemos visto, la pregunta que presenta queda sin respuesta, pero, ¿debemos interpretar por ello que es una pregunta retórica? No necesariamente. Podemos pensar que nos enfrentamos a verdaderas preguntas y que es nuestro deber contestarlas. El Selkirk de Borges parece, en ese sentido, reconocer su imposibilidad de comunicarse con el otro que lo habita, pero comprometido, de cualquier manera, a seguir intentándolo.

Llama la atención que Cowper y Borges, admiradores de Homero, se centren no en el aspecto heroico del vagabundo de los mares, o en el alivio del viajero que regresa a casa, sino en su contraparte, el náufrago espantado, abandonado en una isla desierta o que, salvado, no logra recuperarse de la experiencia de soledad y de abandono. Sus textos nos permiten ver los claroscuros del héroe y del aventurero, y recordar que no están hechos de una pieza. En cierto momento del Robinson Crusoe, en una cueva, el protagonista descubre unos ojos que lo miran, y conjetura, aterrorizado, que pueden ser del Diablo. Poco después, se dará cuenta que lo mira un macho cabrío moribundo: "I saw lying on the Ground a most frightful old He-goat, just making his Will, as we say, and gasping for life, and dying indeed of meer [sic] old Age" (Defoe, 1994: 129).

Al final de un soneto hermano de "Alexander Selkirk", "Odisea, libro vigésimo tercero" (Borges, 1978: 213), Borges coloca una pregunta hasta cierto punto semejante 


\section{$78 \square$ EL ESPEJO Y LA MÁSCARA: DOS VERSIONES DE ALEXANDER SELKIRK}

a la que se hace el marinero escocés, esta vez con respecto a Odiseo, después de haber regresado a Ítaca (vv. 11-14): "pero ¿dónde está aquel hombre / que en los días y noches del destierro / erraba por el mundo como un perro / y decía que Nadie era su nombre?". Incluso Odiseo puede estar dividido después de su regreso. Vale la pena percatarse de que Borges hace aquí uso en dos de sus versos de los mismos sustantivos que constituyen la rima del dístico de "Alexander Selkirk": "hombre" y "nombre". La rima en ambos poemas apunta a la falta de conexión entre el individuo y su identidad. Por lo demás, el argentino estaba perfectamente consciente de las analogías entre sus dos poemas, y así lo expresó en el prólogo de El otro, el mismo, el poemario donde ambos están uno al lado del otro: "Alexander Selkirk" no difiere notoriamente de "Odisea, libro vigésimo tercero" (Borges, 1978: 167).

A través de esta asociación explícita con Odiseo, establecida por el mismo Borges, su Selkirk se convierte no sólo en la imagen de cierto tipo de individuo, indefenso e irremediablemente escindido por su circunstancia. El personaje es también la imagen del héroe que, aunque exitoso, también está dividido. Valiéndonos de Camus, podemos decir que todos somos varias personas, Selkirk, Odiseo y Sísifo, y que el intento eterno de trascender nuestra condición no sólo es condena, sino también destino asumido.

En un ensayo titulado "Lo que no se dice en un poema de Borges", uno de los pocos en los que se hace alusión a "Alexander Selkirk", aunque muy superficialmente, Carlos Cortínez (1979) trata de desenmascarar la reticencia del autor argentino y desarmar uno de los crípticos poemas amorosos de éste para descubrir la experiencia real de Borges. Cortínez escribe en las páginas finales de su texto: "Son tantas las alusiones al tema [del desamor] en la obra de Borges, vinculadas a referencias autobiográficas, que nos sentimos casi obligados a afirmar que ellas se refieren a una misma experiencia infortunada que le acaeció a él, Jorge Luis Borges" (1979: 217). Puede ser así, pero tales explicaciones son fáciles de encontrar y, por ello, hasta cierto punto, poco interesantes. No es raro que los escritores hablen de la relación entre su vida y sus poemas. Por mucho que aceptemos que la voz del poema no es idéntica a la del poeta, en ocasiones parece que el poeta busca identificarse con esa voz. En el soneto "A quien ya no es joven" (Borges, 1978: 211), también rimado al estilo francés, que precede a "Alexander Selkirk" en El otro, el mismo, Borges parece desenmascararse cuando dice, en los vv. 5-14:
¿A qué sigues buscando en el brumoso
bronce de los hexámetros la guerra
si están aquí los siete pies de tierra,
la brusca sangre y el abierto foso?

Aquí te acecha el insondable espejo

que soñará y olvidará el reflejo

de tus postrimerías y agonías. 
Ya te cerca lo último. Es la casa

donde tu breve y lenta tarde pasa

y la calle que ves todos los días.

El comentario de Cortínez parece innecesario ante tal declaración. La casa donde la voz habita no parece distinta de la isla de Selkirk. Lo mismo puede decirse de Cowper. Tal vez su poema más antologado sea "The Castaway". En él, se nos describe la tragedia de un marinero que ha caído al océano durante una tormenta y a quien sus compañeros desde el barco son incapaces de salvar. En la última estrofa, la voz poética usa al hombre que se ahoga irremediablemente para hablar de todos los seres humanos, pero también de sí misma (Cowper, 1999: 5 vv. 61-66):

No voice divine the storm allay'd,

No light propitious shone,

When, snatched from all effectual aid,

We perish'd, each, alone:

But I, beneath a rougher sea,

And whelm'd in deeper gulfs than he.

Al leer estos versos, es difícil no pensar que la voz poética se identifica con Cowper, suicida fracasado y depresivo recluso durante la mayor parte de su vida. No obstante, aunque simpatizo con su dilema, me parece un poema más interesante, por más reticente, su composición sobre Alexander Selkirk. Tanto Cowper como Borges decidieron, al menos en estos poemas, no escribir poesía confesional, sino entregar a los lectores la representación de una experiencia a través de la prosopopeya. Querer encontrar al poeta detrás de ésta me parece, así, un ejercicio que hasta cierto punto nos distrae del texto, reflejo o máscara no sólo de un momento de su creador, sino de las personas que nos habitan.

En otro de sus ensayos sobre la traducción, "El enigma de Edward Fitzgerald", Borges se maravilla ante la traducción que Fitzgerald (un poeta tan olvidado como Cowper, si no es que más) hizo de las rubayat de Jayyam, y que publicó con el título Rubáiyát of Omar Khayyám, The Astronomer Poet of Persia, un clásico de la poesía victoriana. Como un intento de explicarse este fenómeno literario, el argentino presenta, entre otras, una explicación sobrenatural: "Isaac Luria el León enseñó que el alma de un muerto puede entrar en un alma desventurada para sostenerla o instruirla; quizá el alma de Umar se hospedó, hacia 1857, en la de Fitzgerald" (Borges, 1974: 690). Yo me atrevería a decir que tal explicación se puede usar como metáfora de la relación entre Borges y Cowper, a través de la figura de Selkirk. En el monólogo dramático del argentino, que a su modo también puede ser considerado una traducción, en la medida en la que ofrece una versión del poema de Cowper en cuanto a estructura e imágenes, Borges no sólo habla detrás de Selkirk, sino que también hace hablar al Selkirk de Cowper, y al propio Cowper. Pero también puede hablar por nosotros y por nuestros 
problemas profundos no resueltos, y por nuestro intento de solucionarlos. Y, finalmente, más allá de ello, también construye un soneto que le permite manejar la experiencia de la soledad y del desamparo con la ilusión del dominio sobre la palabra, de una forma tan eficiente como puede ser escribir una "autobiografía espiritual". Por medio de la creación o el análisis de un artificio verbal, podemos descubrirnos y, también, olvidarnos de nosotros.

Al final de The Rime of The Ancient Mariner, que ya hemos mencionado, el hombre que ha sido elegido para escuchar el relato del viejo marino se aleja "A sadder and a wiser man" (Coleridge, 1992: 65 v. 624). La frase se puede aplicar al lector de los dos poemas que he tratado de comentar en cierto detalle aquí. La poesía no es sólo "la Palabra, libertad que se inventa y que me inventa cada día", como diría Octavio Paz (1998: 72); es también un "ajedrez misterioso, cuyo tablero y cuyas piezas cambian como en un sueño” (Borges, 1978: 169), y que jugamos leyéndolo.

\section{Bibliografia}

Aquien, Michèle; y Molinié, Georges. (1999). Dictionnaire de rhétorique et de poétique. Varese: Librairie Générale Française.

Austen, Jane. (2002). Sense and Sensibility (Claudia L. Johnson, Ed.). S. 1.: W. W. Norton and Company.

Borges, Jorge Luis. (1974). Obras completas. Buenos Aires: Emecé.

Borges, Jorge Luis. (1978). Obra poética. Buenos Aires: Emecé.

BorGES, Jorge Luis. (1996). Obras completas 4. Barcelona: Emecé.

Borges, Jorge Luis. (1997). Introducción a la literatura inglesa (María Esther Vázquez, Colab.). Buenos Aires: Emecé.

Borges, Jorge Luis. (1999a). Euvres complètes 2 (Jean Pierre Bernès, Ed.). Lonrai: Gallimard.

Borges, Jorge Luis. (1999b). Selected Non-Fictions (Eliot Weinberger, Ed.; Esther Allen, Suzanne Jill Levine y Eliot Weinberger, Trads.). S. 1.: Penguin Books. Borges, Jorge Luis. (2010). Obras completas. Edición crítica. 2. (anotada por Rolando Costa Picazo). Buenos Aires: Emecé.

Byron, Glennis. (2003). Dramatic Monologue. S. 1.: Routledge.

CAmus, Albert. (2019). Le mythe de Sisyphe. S. 1.: Gallimard.

Cervera Salinas, Vicente. (1992). La poesía de Jorge Luis Borges: Historia de una Eternidad. Murcia: Universidad de Murcia.

Coleridge, Samuel Taylor. (1992). The Major Works (H. J. Jackson, Ed.). Oxford: Oxford University Press.

Cooke, Edward. (1994 [1712]). "Rescue of Alexander Selkirk from Juan Fernandez Island”. En Daniel Defoe, Robinson Crusoe (Michael Shinagel, Ed.). 230. S. 1.: W. W. Norton and Company. 
Cortínez, Carlos. (1979). "Lo que no se dice en un poema de Borges". Revista Canadiense de Estudios Hispánicos, 3(3), 201-218.

COWPER, William. (1999). Poetry (Michael Bruce, Ed.). Guernsey: Everyman.

Crolla, Adriana. (2007). "Odiseo-Ulises-Sísifo: 'fatti non foste a viver come bruti"'. Revista de Culturas y Literaturas Comparadas, 1(0), 236-251.

Defoe, Daniel. (1994). Robinson Crusoe (Michael Shinagel, Ed.). S. 1.: W. W. Norton and Company.

Domínguez CaParrós, José. (1999). Diccionario de Métrica Española. Madrid: Alianza Editorial.

Greenblatt, Stephen; NogGLE, James; y LiPKING, Lawrence (Eds.). (2012). The Norton Anthology of English Literature. The Restoration and The Eighteenth Century. Estados Unidos de América: W. W. Norton and Company.

GrEENE, Roland; y CusHMAN, Stephen (Eds.). (2012). The Princeton Encyclopedia of Poetry and Poetics. Princeton: Princeton University Press.

HeLfT, Nicolás. (1997). Jorge Luis Borges. Bibiografía completa. Buenos Aires: Fondo de Cultura Económica.

Homer. (1998). Odyssey (A. T. Murray y George E. Dimock, Trads.). Ann Arbor: Harvard University Press.

Homero. (2007). Odisea (Carlos García Gual, Introd.; José Manuel Pabón, Trad.). Barcelona: RBA Libros.

JoneS, Julie. (1986). "Borges and Browning: A Dramatic Dialogue". En Carlos Cortínez (Ed.), Borges The Poet. 207-218. Fayetteville: The University of Arkansas Press.

Langbaum, Robert. (1963). The Poety of Experience. Estados Unidos de América: W. W. Norton and Company.

PAZ, Octavio. (1998). Libertad bajo palabra (Enrico Mario Santi, Ed.). Madrid: Cátedra.

Rogers, Woodes. (1994 [1712]). “Account of Alexander's Selkirk Solitary Life on Juan Fernandez Island for Four Years and Four Months". En Daniel Defoe, Robinson Crusoe (Michael Shinagel, Ed.). 230-235. Estados Unidos de América: W. W. Norton and Company.

Rosato, Laura; y Álvarez, Germán (Eds.). (2010). Borges, libros y lecturas. Buenos Aires: Ediciones Biblioteca Nacional.

SPACKS, Patricia Meyer. (1976). "The Soul's Imaginings: Daniel Defoe, William Cowper". PMLA, 91(3). 420-435.

SteELE, Richard. (1994 [1713]). “On Alexander Selkirk”. En Daniel Defoe, Robinson Crusoe (Michael Shinagel, Ed.). 235-238. Estados Unidos de América: W. W. Norton and Company. 